\title{
Post-burn tarsal tunnel syndrome response to extracorporeal shock wave therapy
}

\author{
DOI: https://doi.org/10.5114/pq.2020.96229
}

\author{
Zakaria M.E. Mowafy', Mohamed A.M. Nasr ${ }^{2}$, Khadra M. Ali ${ }^{1}$, Ahmed M.A. Sherief ${ }^{1,3}$ \\ ${ }^{1}$ Department of Physical Therapy for Surgery, Faculty of Physical Therapy, Cairo University, Giza, Egypt \\ ${ }^{2}$ Department of Plastic Surgery, Faculty of Medicine, Zagazig University, Zagazig, Egypt \\ ${ }^{3}$ Department of Integumentary System Disorders, Faculty of Physical Therapy, South Valley University, Qena, Egypt
}

Abstract

Introduction. To evaluate the effect of extracorporeal shock wave therapy (ESWT) on electrophysiological responses in patients suffering from tarsal tunnel syndrome after burn.

Methods. Overall, 40 male and female individuals with tarsal tunnel syndrome after a burn injury were equally divided into 2 groups. Group 1 received ESWT in addition to a routine physical therapy program, which consisted of stretching of calf muscles followed by pulsed ultrasound, ice massage, and ankle pump exercise. Group 2 received the routine physical therapy program only. The area of popliteal fossa (slightly laterally) was outlined and 100 impulses per $\mathrm{cm}^{2}$ and another 100 impulses per $\mathrm{cm}^{2}$ were administered over the area behind and above the medial malleolus. The 2 areas were administered every 2 weeks for 3 months as a total period of treatment. Sensory and motor nerve conduction velocities of the lateral and medial plantar branches of the tibial nerve were measured before the treatment and after 3 months.

Results. There was an improvement and a significant decrease in the prolonged motor and distal latencies of the 2 branches of the posterior tibial nerve in the ESWT group compared with group $2(p<0.05)$.

Conclusions. ESWT is effective in treating patients suffering from tarsal tunnel syndrome after burn as evidenced by decreasing the prolonged motor and sensory distal latencies of the 2 branches of the posterior tibial nerve.

Key words: extracorporeal shock wave therapy, tarsal tunnel syndrome, burn, nerve conduction velocity

\section{Introduction}

Burned patients have many dysfunctions owing to the affection of original protective skin structures, damage to the blood system, and severe metabolic disorders associated with abnormal capillary permeability plus extravascular oedema with cutaneous ischaemia. Injuries secondary to burn also lead to nervous system destruction. The most common results of a burn injury and, at the same time, healing problems are weakness and loss of sensation. Nerve injuries may be the main cause of these symptoms. Burn contractures, affecting the physical functions of burned patients, can result from the previously mentioned burn complications, as well as a damage to the lymphatic system. These contractures will delay healing of burn wounds in both acute and chronic phases [1-4].

Peripheral neuropathies observed after thermal injuries mostly affect the nerves of the burned areas; they are also common in individuals with burn injuries exceeding $20 \%$ of total body surface area. Moreover, usually 3-7 nerves are affected in each individual during peripheral neuropathy. This results from multiple mononeuropathy caused by crush syndrome. Polyneuropathy is common after thermal injuries leading to electrophysiological symptoms which are present in the first week (post-burn) in injured and even uninjured areas; the changes in nerve functions originate from inflammation caused by thermal injuries. Peripheral neuropathies are common in alcoholics, diabetics, and aged patients owing to lesser mobility and their low nerve pressure tolerance as well [5-7].

One of the causes of peripheral neuropathies in burned patients is the hypermetabolic response. The basal metabolic rate (BMR) of burned individuals is more than double the one of healthy individuals. This contributes to the excess of circulating catecholamines, which increase the sympathetic tone, leading to increased systemic vascular resistance and decreased cutaneous, muscular, and endoneurial blood flow (nerve blood flow), resulting in nerve function problems [8-11].

Burns affecting more than $20 \%$ of total body surface area are associated with scar formation, which may lead to contractures, decreased range of motion, and entrapment syndromes. Carpal (CTS) and tarsal (TTS) tunnel syndromes are examples of entrapment syndromes which may occur after burn in the upper and lower limbs, respectively. TTS is a compression neuropathy of the tibial nerve within the tarsal tunnel, which is located along the inner leg, behind the medial malleolus. Patients with TTS typically complain of numbness in the foot radiating to the big toe and the first three toes, pain, burning, electrical sensations, and tingling over the base of the foot and the heel [8-11].

Electrophysiology was used in the $18^{\text {th }}$ century by Galvani. Electrophysiological studies of nerves and muscles are extremely important in many clinical practices. Hodes et al. [12] presented the first clinically-based discussion of conduction velocity analysis and aroused a great interest in the subject of electrophysiological testing [11-15].

Shock wave therapy, known as extracorporeal shock wave therapy (ESWT), is clinically recognized for the treatment of chronic soft tissue injuries and certain bone disorders. It is well defined as a non-evasive, non-electrical highenergy sound wave that penetrates the body via a hand-held

Correspondence address: Ahmed Abd El Fadiel Sherief, Department of Integumentary System Disorders, Faculty of Physical Therapy, South Valley University, Kilo 6 Qena Safaga Road, Qena, Egypt, e-mail: dr_ahmed_beh@yahoo.com 
probe. The shock waves lead to a rapid increase in blood flow to the treated area and therefore interrupt the formation and building-up of scar tissue, particularly in chronic disorders. ESWT is effective in breaking down adhesion and scar tissue. It is proven that scar tissue is not as elastic as normal tissue, which prevents normal function during normal movement. Breaking down scar tissue is a key stone to return to normal function and to reduce pain [16-19].

ESWT can be effective in handling and re-establishing normal function in a wide range of soft tissue and bone disorders. These may include chronic connective tissue dysfunction, frozen shoulder, tennis elbow, heel spur, and supraspinatus tendinitis [20-22].

Many studies have been performed to assess the effect of shock wave in individuals suffering from different types of neuropathies, like peripheral neuropathy, diabetic neuropathy, and CTS. Evidence-based research proves that 3-4 treatment sessions with shock wave to heel spur, soft tissue injuries, and neuropathies allowed to decline pain and achieve normal function in more than $80 \%$ of patients $[3,5,19,20]$.

Regardless of new therapies, the management of TTS is still complicated, and there is no definite treatment effective in all cases, which present variable underlying mechanisms. Oral medications and local injections of corticosteroids have many adverse effects. The purpose of this study was to evaluate the effect of shock wave in patients suffering from post-burn TTS as ESWT may provide a safe and non-invasive treatment and open the road for many researchers to perform more studies on that area. It was hypothesized that there was no effect of ESWT on the electrophysiological responses in post-burn TTS patients.

\section{Subjects and methods}

\section{Design of the study}

The study was designed as a prospective, randomized, controlled trial. It was performed between July 2018 and February 2019.

\section{Participants}

The study was carried out among 40 outpatient individuals with chronic burn in their lower extremity (30 men and 10 women). Their age ranged from 20 to 35 years. They were selected from the Cairo University hospitals and OmAl-Misryeen hospital. The percentage of total body surface area burned in the participants exceeded $20 \%$. They were diagnosed with second or third degree burns with a secondary complication of TTS. The patients reported no other pathological conditions, except for neuropathies. They showed the necessary cooperation to enable the investigator to secure the required data. The participants were divided into 2 equal groups. Group 1 (study group) received ESWT in addition to a routine physical therapy program that consisted of stretching of calf muscles followed by pulsed ultrasound, ice massage, and ankle pump exercise. Group 2 (control group) received the routine physical therapy program only.

\section{Inclusion criteria}

All patients had the following characteristics: age ranging between 20 and 35 years, lower limb burn with the percentage of the total body surface area burned of more than $20 \%$, and a diagnosis of a second or third degree burn complicated with TTS confirmed in an electroneurographic exami- nation, as well as in a physical examination which included Tinel's test. All participants were non-smokers and continued to receive their own medications prescribed by their physicians.

\section{Exclusion criteria}

Patients with a history of distal tibial fracture, ankle fracture, lumbar radiculopathy, fibromyalgia, diabetes mellitus, skin diseases, or peripheral vascular diseases, as well as pregnant women and individuals receiving oral anticoagulants or steroid injections were excluded.

\section{Randomization}

Every individual was informed about the nature, purpose, and benefits of the research and their right to withdraw or refuse at any time. The patients were randomly assigned into 2 equal groups (control group and study group) with the use of a computer-based randomization program. No subject dropped out from the study after randomization. The patients were blinded about which group they were allocated to.

\section{Instrumentation}

\section{Assessment device}

The equipment used in the measurements in this research was the Neuropack 2 MEB-7102K 2 channels EMG-EP machine (Nihon Kohden Corp. Tokyo, Japan). It allowed to obtain an unbiased assessment of the sensory (SCV) and motor (MCV) conduction velocity.

\section{Treatment devices}

The therapeutic equipment and tools used in this research were a MASTERPULS MP200 shock wave device (StorzMedical, Tägerwilen, Switzerland) and a CWM-302-digisonic therapeutic ultrasound device (Chungwoo Medical, Seoul, South Korea).

\section{Procedures}

\section{Assessment procedures}

\section{Motor conduction velocity measurement}

\section{Recording electrodes}

For the medial plantar branch, the recording electrode was placed between the heel and base of the first metatarsal bone over the main bulk of the abductor hallucis muscle. The positive electrode was placed distally over the ball of the big toe, and the ground electrode was placed between the stimulating and recording electrodes around the ankle area [4, $8,10]$. For the lateral plantar branch, the recording electrode was placed below the head of the third metatarsal bone over the main bulk of the adductor hallucis muscle. The positive electrode was placed distally over the tip of the third toe, and the ground electrode was placed around the ankle area [1, 8, $10,17]$.

\section{Stimulating electrodes}

The stimulating cathode in the distal stimulation was placed behind and above the medial malleolus, $8 \mathrm{~cm}$ prox- 
imally to the active recording electrode to provide a standardized distal latency segment. In the proximal stimulation, the stimulating cathode was placed in the centre of the popliteal fossa. For both stimulation sites, the positive electrode was proximal to the negative electrode $[1,10,13,14]$.

\section{$\underline{\text { Sensory conduction velocity measurement }}$}

\section{Recording electrodes}

For the medial plantar branch, the recording electrode was placed above and behind the medial malleolus over the posterior tibial nerve while. For the lateral plantar branch, the recording electrode was placed above and behind the medial malleolus over the posterior tibial nerve. The positive electrode was placed $3 \mathrm{~cm}$ proximally from the active recording electrode, and the ground electrode was placed between the stimulating and recording electrodes around the ankle area. An averaging recording technique was used in the sensory recording.

\section{Stimulating electrodes}

For the medial plantar branch, the stimulating electrode was placed around the big toe. For the lateral plantar branch, it was placed around the little toe, with the active electrode proximal to the reference one. The recording and stimulating electrodes were moistened with gel, while the ground electrode was soaked in water; all electrodes were firmly fixed in their places $[13,14,17,18]$.

The tibial nerve MCV and SCV measurement was performed as follows:

- The recordings were conducted in an air-conditioned room, at a temperature between $24^{\circ} \mathrm{C}$ and $28^{\circ} \mathrm{C}$; therefore, the room temperature variations along the distribution of the tested nerve were decreased. Heating of the tested limb was achieved by applying massage for 5 minutes to further decrease the temperature disparity.

- The on-off switch of the Neuropack 2 MEB-7102K machine was turned on.

- The Neuropack 2 MEB-7102K program CD was put in to open the software.

- The availability of all needed electrodes was checked. Then, they were connected either to the negative or to the positive input of the electrode junctional box active channels $[1,2,8,10,19]$.

- For MCV, throughout all recordings, the sensitivity used was $1 \mathrm{mV} /$ division, and the sweep speed was $3 \mathrm{~ms}$, while the intensity of the stimulus equalled 1-50 mA; stimuli were performed to obtain a supra-maximal recording amplitude. A tape was used to measure the distances between the points, while a marker pen served to indicate the stimulation points to allow nerve conduction velocity calculation. Nerve conduction velocity was determined with the following formula:

$$
\text { distance }(\text { in } \mathrm{cm}) \times 10 / \text { conduction velocity }=\mathrm{L} 1-\mathrm{L} 2
$$

where $\mathrm{L} 1$ is the proximal latency and $\mathrm{L} 2$ is the distal latency $[5,10,12,14]$.

- For SCV, ring electrodes were applied for the medial plantar branch on the big toe and for the lateral plantar branch on the little toe (cathode proximal to anode). The recording was obtained from the main trunk of the posterior tibial nerve behind and above the medial malleolus. An averaging technique was used. Sensory distal latency (SDL) and SCV were obtained and recorded [2, 4, 5, 14, 17, 23].

\section{Treatment procedures}

Group 1 received ESWT plus a routine physical therapy program, while group 2 received a routine physical therapy program only.

\section{Shock wave therapy application}

The patient was placed in a supine lying position with both hips slightly rotated laterally and flexed, both knees slightly flexed (only $10^{\circ}$ ), and both ankles slightly plantar flexed, with pillows under the knees and head. This was to achieve full relaxation of the participants. The popliteal fossa (slightly laterally) was outlined and 100 impulses per $\mathrm{cm}^{2}$ were administered every 2 weeks for 3 months; another 100 impulses per $\mathrm{cm}^{2}$ were administered over the area behind and above the medial malleolus at a frequency of $6 \mathrm{~Hz}$ and intensity of 1.5 bar [1, 10, 13, 14, 19].

\section{Physical therapy program}

The physical therapy program for both groups consisted of gentle stretching of calf muscles followed by therapeutic pulsed ultrasound (parameters: $3 \mathrm{MHz}, 0.84 \mathrm{~W} / \mathrm{cm}^{2}$, continuous, 3 minutes), ice massage for 5 minutes, and ankle pump exercise (for 5 minutes, 3 sessions per week per 12 weeks) $[10,13,14]$.

Before the experiment, the SCV and MCV of the posterior tibial nerve for each individual were recorded in both groups. ESWT was applied every 2 weeks for 3 months, after which the second (final) MCV and SCV recording were taken.

The pre- and post-experimental measurements were performed during the same time of the day to decrease variability. The step-by-step procedure for data recording was identical to that during the pre-experimental measurement of the SCV and MCV of the posterior tibial nerve, taken before the treatment as an initial record and then after 3 months as a second (last) record in the 2 groups.

The collected data were input into a personal computer to analyse the statistics. Descriptive statistics as standard deviation, mean, maximum, and minimum were calculated for both groups. The $t$-test was performed to compare the mean difference between both groups after and before the intervention, as well as within each group. The alpha point of 0.05 was used as the level of significance [24].

\section{Ethical approval}

The research related to human use has complied with all the relevant national regulations and institutional policies, has followed the tenets of the Declaration of Helsinki and the Consolidated Standards of Reporting Trials, and has been approved by the institutional review board at the Faculty of Physical Therapy, CairoUniversity (No.P.T.REC/012/001941).

\section{Informed consent}

Informed consent has been obtained from all individuals included in this study.

\section{Results}

As displayed in Table 1, the mean value of the motor distal latency (MDL) of the medial plantar branch in the study group equalled $10.4500 \pm 1.0511 \mathrm{~ms}$ before the experiment and decreased to $6.1200 \pm 0.4365 \mathrm{~ms}$ after the treatment. This showed a significant decrease in the MDL of the medial plantar branch $(p<0.0001)$. In group 2 , the mean value of the MDL 
Table 1. Comparison of mean motor distal latency values $(\mathrm{ms})$ of the medial plantar branch before and after treatment in groups 1 and 2

\begin{tabular}{|l|c|c|c|c|c|c|c|c|}
\cline { 2 - 8 } \multicolumn{1}{c|}{} & \multicolumn{2}{c|}{ Before treatment } & \multicolumn{2}{c|}{ After treatment } & \multirow{2}{*}{ Mean difference } & $t$ & $p$ & Level of significance \\
\cline { 2 - 9 } \multicolumn{1}{c|}{} & Mean & $S D$ & Mean & $S D$ & & & \\
\hline $\begin{array}{l}\text { Study group } \\
\text { (ESWT + PT) }\end{array}$ & 10.4500 & 1.0511 & 6.1200 & 0.4365 & 4.33000 & 14.73 & $<0.0001$ & $\begin{array}{c}\text { Highly significant } \\
\text { decrease }\end{array}$ \\
\hline $\begin{array}{l}\text { Control group } \\
\text { (PT only) }\end{array}$ & 10.4450 & 1.0556 & 10.4600 & 1.0655 & -0.015000 & -0.04 & 0.969 & Non-significant \\
\hline
\end{tabular}

ESWT - extracorporeal shock wave therapy, PT - physical therapy

Table 2. Comparison of mean sensory distal latency values (ms) of the medial plantar branch before and after treatment in groups 1 and 2

\begin{tabular}{|l|c|c|c|c|c|c|c|c|}
\cline { 2 - 8 } \multicolumn{1}{c|}{} & \multicolumn{2}{c|}{ Before treatment } & \multicolumn{2}{c|}{ After treatment } & \multirow{2}{*}{ Mean difference } & $t$ & $p$ & Level of significance \\
\cline { 2 - 8 } \multicolumn{1}{c|}{} & Mean & $S D$ & Mean & $S D$ & & \\
\hline $\begin{array}{l}\text { Study group } \\
\text { (ESWT + PT) }\end{array}$ & 10.3800 & 1.7562 & 6.6340 & 0.6780 & 3.74600 & 7.71 & $<0.0001$ & $\begin{array}{c}\text { Highly significant } \\
\text { decrease }\end{array}$ \\
\hline $\begin{array}{l}\text { Control group } \\
\text { (PT only) }\end{array}$ & 10.2300 & 0.6120 & 10.2350 & 0.6545 & -0.005000 & -0.02 & 0.983 & Non-significant \\
\hline
\end{tabular}

ESWT - extracorporeal shock wave therapy, PT - physical therapy

Table 3. Comparison of mean motor distal latency values $(\mathrm{ms})$ of the lateral plantar branch before and after treatment in groups 1 and 2

\begin{tabular}{|l|c|c|c|c|c|c|c|c|}
\cline { 2 - 8 } \multicolumn{1}{c|}{} & \multicolumn{2}{c|}{ Before treatment } & \multicolumn{2}{c|}{ After treatment } & \multirow{2}{*}{ Mean difference } & $t$ & $p$ & Level of significance \\
\cline { 2 - 8 } \multicolumn{1}{c|}{} & Mean & $S D$ & Mean & $S D$ & & \\
\hline $\begin{array}{l}\text { Study group } \\
\text { (ESWT + PT) }\end{array}$ & 10.2850 & 0.6845 & 9.7050 & 0.4051 & 0.580000 & 2.82 & $<0.0001$ & Significant decrease \\
\hline $\begin{array}{l}\text { Control group } \\
\text { (PT only) }\end{array}$ & 10.3800 & 0.6120 & 10.3850 & 0.6067 & -0.005000 & -0.02 & 0.982 & Non-significant \\
\hline
\end{tabular}

ESWT - extracorporeal shock wave therapy, PT - physical therapy

Table 4. Comparison of mean sensory distal latency values (ms) of the lateral plantar branch before and after treatment in groups 1 and 2

\begin{tabular}{|l|c|c|c|c|c|c|c|c|}
\cline { 2 - 8 } \multicolumn{1}{c|}{} & \multicolumn{2}{c|}{ Before treatment } & \multicolumn{2}{c|}{ After treatment } & \multirow{2}{*}{ Mean difference } & $t$ & $p$ & Level of significance \\
\cline { 2 - 9 } \multicolumn{1}{c|}{} & Mean & $S D$ & Mean & $S D$ & & \\
\hline $\begin{array}{l}\text { Study group } \\
\text { (ESWT + PT) }\end{array}$ & 10.4110 & 0.5216 & 6.9300 & 0.5251 & 3.48100 & 18.22 & $<0.0001$ & $\begin{array}{c}\text { Highly significant } \\
\text { decrease }\end{array}$ \\
\hline $\begin{array}{l}\text { Control group } \\
\text { (PT only) }\end{array}$ & 10.4142 & 0.6612 & 10.4300 & 0.6404 & -0.015800 & -0.07 & 0.947 & Non-significant \\
\hline
\end{tabular}

ESWT - extracorporeal shock wave therapy, PT - physical therapy

of the medial plantar branch equalled $10.4450 \pm 1.0556 \mathrm{~ms}$ before the treatment and became $10.4600 \pm 1.0655 \mathrm{~ms}$ after the treatment. This showed a non-significant difference in the MDL of the medial plantar branch $(p>0.05)$.

Table 2 shows that the mean value of SDL of the medial plantar branch in the study group equalled $10.3800 \pm$ $0.7562 \mathrm{~ms}$ before the experiment and decreased to 6.6340 $\pm 0.6780 \mathrm{~ms}$ after the treatment. This showed a significant decrease in the SDL of the medial plantar branch $(p<$ $0.0001)$. In group 2, the mean value of the SDL of the medial plantar branch equalled $10.2300 \pm 0.6120 \mathrm{~ms}$ before the treatment and became $10.2350 \pm 0.6545 \mathrm{~ms}$ after the treatment. This showed a non-significant difference in the SDL of the medial plantar branch $(p>0.05)$.

As presented in Table 3, the mean value of the MDL of the lateral plantar branch in group 1 equalled $10.2850 \pm$ $0.6845 \mathrm{~ms}$ before the experiment and decreased to 9.7050 $\pm 0.4051 \mathrm{~ms}$ after the treatment. This showed a significant reduction in the MDL of the lateral plantar branch $(p<0.0001)$. branch equalled $10.3800 \pm 0.6120 \mathrm{~ms}$ before the treatment and became $10.3850 \pm 0.6067 \mathrm{~ms}$ after the treatment. These results show a non-significant difference in the MDL of the lateral plantar branch $(p>0.05)$.

Table 4 shows that the mean value of the SDL of the lateral plantar branch in group 1 equalled $10.4110 \pm 0.5216 \mathrm{~ms}$ before the experiment and decreased to $6.9300 \pm 0.5251$ ms after the treatment. This showed a highly significant decrease in the SDL of the lateral plantar branch $(p<0.0001)$. In group 2, the mean value of the SDL of the lateral plantar branch equalled $10.4142 \pm 0.6612 \mathrm{~ms}$ before the treatment and became $10.4300 \pm 0.6404 \mathrm{~ms}$ after the treatment. This showed a non-significant difference in the SDL of the lateral plantar branch $(p>0.05)$.

\section{Discussion}

After a burn injury, BMR is decreased owing to a reduced oxygen supply to the cell. This decrease is temporary and is followed by a gradual increase to the normal value. After that, 
BMR continues to rise to at least double the normal value. The phase at which BMR is decreased after the burn is called the ebbed phase, while the second phase, at which BMR increases, is referred to as the flow phase; it is caused by an increased activity of the adrenal medulla to release catecholamines [5, 8, 13, 14].

Vascular burn complications that disturb the peripheral body parts result from the predominating sympathetic tone and the circumferential third degree burn. Together with a decreased arterial blood flow due to arterial compression, the composite effects of the predominating sympathetic tone and the circumferential third degree burn can lead to ischaemia and the 'five P's' (pain, pallor, pulselessness, paraesthesia, and paralysis) [1, 3, 13, 17].

Compression neuropathies can occur during surgery from the sustained application of an elastic tourniquet to create a bloodless area. The direct compression of the underlying nerves and ischaemic injury to the tissue distal to the tourniquet are two possible mechanisms of injury. Nerves that are superficial and at a substantial risk for damage are the ulnar nerve at the elbow and the superficial branch of the radial nerve on the dorsum of the hand in the upper limb, in addition to the tibial nerve and the common peroneal nerve at the fibular head in the lower limb [3, 10, 13, 17, 24].

Evidence-based research shows that ESWT has become a new effective modality in the treatment of many acute and chronic soft tissue injuries like tendinitis, tennis elbow, plantar fasciitis, and hypertrophic scar [23]. It is very important to know the exact parameters of the shock wave used in the treatment; however, the mechanism of how the shock wave works remains unclear [25]. The shock wave has two effects. The first is the primary effect which results from the mechanical energy concentrated at the targeted treated area. The second (secondary) effect results from cavitation [26].

Some studies performed on animals revealed that ESWT might efficiently support healing because it contributes to the process of angiogenesis and increases blood flow in the treated area [27]. Shock wave also stimulates a serial biological response which helps resolve inflammation [28]. Owing to substance $P$ release, ESWT plays a role in pain relief [28]. It may enhance the formation of new blood vessels and regulate the inflammatory process [29].

One of the hypotheses concerning ESWT effects is that it supports nitric oxide (NO) production owing to the stimulation of neuronal NO synthase in the tissue around the median nerve and reduces topical inflammation, thus decreasing pressure on median nerve [30]. Another mechanism described in ESWT studies is pain transformation reduction in the nervous system as a result of an increase in NO level due to raised neuronal NO synthase. In this hypothesis, NO affects the nerve cell membrane, opening potassium channels and reducing the entrance of calcium, which results in hyperpolarization of the cell membrane and controls pain transmission [31, 32]. In addition, it is possible that NO produced by neuronal NO synthase acts as an opioid and reduces pain [33].

Shock wave has a depressing effect in declining the dominant sympathetic tone in burned patients, decreasing the reflex muscle spasm, increasing peripheral circulation, ameliorating oxygen supply, and increasing lymphatic clearing. It also raises nutrient supply and reduces the concentration of metabolites, muscle fatigue, oedema, inflammation, and compressive ischaemic pain. It helps accelerate wound healing and scar maturation, as well as improves nerve functions, motion, and physical functions of the burned patients, allowing them to quickly become productive citizens again [34].
In our trial, there was no significant difference in the MDL or SDL of both branches between the groups before treatment. In the study group, the MDL and SDL of the medial plantar branch decreased after the treatment to $6.1200 \pm 0.4365 \mathrm{~ms}$ and $6.6340 \pm 0.6780 \mathrm{~ms}$, respectively, reflecting significant differences $(p<0.0001)$. However, the same readings for the control group after the treatment were $10.4600 \pm 1.0655$ $\mathrm{ms}$ and $10.2350 \pm 0.6545 \mathrm{~ms}$, respectively), with no significant differences $(p>0.05)$. Also, in the study group, the MDL and SDL of the lateral plantar branch decreased after treatment to $9.7050 \pm 0.4051 \mathrm{~ms}$ and $6.9300 \pm 0.5251 \mathrm{~ms}$, respectively, revealing significant differences $(p<0.0001)$. The same readings for the control group after the treatment were $10.3850 \pm 0.6067 \mathrm{~ms}$ and $10.4300 \pm 0.6404 \mathrm{~ms}$, respectively, without any significant difference $(p>0.05)$. As expected, the results of this study indicate that ESWT was significantly effective in decreasing the MDL and SDL of both the medial and lateral plantar branch of the posterior tibial nerve in post-burn TTS.

Kim et al. [35] performed a meta-analysis to investigate the effect of shock wave on CTS in 6 randomized control trials chosen from PubMed, Embase, and Cochrane Library. The meta-analysis results showed that shock wave enhanced functional outcomes, symptoms, and electrophysiologic parameters in individuals with CTS. The authors recommended more research in that area to verify the long-term effects of shock wave.

Mahran et al. [36] revealed the impact of ESWT on CTS after burn injury. Overall, 30 male and female patients were randomly divided into 2 groups. One group received shock wave plus traditional physical therapy, while the other group received traditional physical therapy only. The study proved that there were non-significant differences in SCV and MCV in the control group before and after the treatment $(p>0.05)$, but there was a highly significant difference in the second records of SCV and MCV in the study group $(p<0.05)$. An improvement was observed in the nerve conduction velocity in the group who received shock wave compared with the control group.

In a study performed on rats, Murata et al. [37] reported that shock wave supported the process of nerve recovery in cases of peripheral nerve damage. They investigated the dorsal root ganglion and used activating transcription factor 3 (ATF3) and growth-associated phosphoprotein (GAP-43) as markers for nerve injury and axonal regeneration, respectively. The average number of neurons immunoreactive for ATF3 increased significantly in the treated rats at all experimental time points, with $78.3 \%$ of those neurons also exhibiting immunoreactivity for GAP-43.

Wu et al. [38] applied shock wave on the sciatic nerve of rats after surgical exposure. They divided the rats into 2 groups. One group received shock wave, while the other group did not. The authors measured MCV before and after the procedure application. They found that MCV decreased in the group who received shock wave so the conclusion was that shock wave might cause reversible demyelination of large diameter nerve fibres.

Hausner et al. [39] performed a study on rats to investigate the effect of shock wave on nerve regeneration after a nerve graft. The rats were divided into 2 groups. One group received shock wave after the nerve graft ( 300 impulses, $3 \mathrm{~Hz}$ ), while the other group did not receive any intervention after the nerve graft. The results of the study showed that the nerve function and the rate of myelination improved in the shock wave group. 
Vahdatpour et al. [40] investigated 60 patients with CTS at the University of Isfahan, Iran. The participants were divided into 2 groups. Group 1 was managed with shock wave and presented a considerable improvement after 3 months of the treatment compared with the control group, who showed no improvement or slight regression. So, the authors concluded that shock wave was a good conservative modality to be used in cases of CTS.

In accordance with the discussion of previous reports in fields related to this study, it can be claimed that the application of ESWT in post-burn TTS decreases the MDL and SDL of the medial and lateral plantar branches of the posterior tibial nerve. This may be because of the depressing effect on the sympathetic tone and the peripheral vasodilatation, resulting in improved nerve functions.

\section{Limitations}

The study was limited by the psychological condition of the patients at the time of the intervention, which might affect the results. Another limitation was the small sample size and potential errors in measuring MCV and SCV. Therefore, more extensive studies regarding the efficacy of ESWT on post-burn TTS with larger samples are needed. Follow-up studies would be of great interest to detect the long-term impact of ESWT and the recurrence of pain.

\section{Conclusions}

ESWT application in post-burn TTS decreases the MDL and SDL of the medial and lateral plantar branches of the posterior tibial nerve. The study demonstrates that ESWT is beneficial in treating patients suffering from TTS after burn.

\section{Disclosure statement}

No author has any financial interest or received any financial benefit from this research.

\section{Conflict of interest}

The authors state no conflict of interest.

\section{References}

1. Garchar DJ, Lewis JE, DiDomenico LA. Hypertrophic sustentaculum tali causing tarsal tunnel syndrome: a case report. J Foot Surg. 2001;40(2):110-113; doi: 10.1016/s1067-2516(01)80053-3.

2. Chung B, Wiley JP. Effectiveness of extracorporeal shock wave therapy in the treatment of previously untreated lateral epicondylitis: a randomized controlled trial. Am J Sports Med. 2004;32(7):1660-1667; doi: 10.1177/0363546503262806.

3. Lee SY, Cheng B, Grimmer-Somers K. The midterm effectiveness of extracorporeal shockwave therapy in the management of chronic calcific shoulder tendinitis. J Shoulder Elbow Surg. 2011;20(5):845-854; doi: 10.1016/ j.jse.2010.10.024.

4. Gerdesmeyer L, Frey C, Vester J, Maier M, Weil L Jr, Weil L Sr, et al. Radial extracorporeal shock wave therapy is safe and effective in the treatment of chronic recalcitrant plantar fasciitis: results of a confirmatory randomized placebo-controlled multicenter study. Am J Sports Med. 2008;36(11):2100-2109; doi: 10.1177/03 63546508324176.

5. Birnbaum K, Wirtz DC, Siebert CH, Heller KD. Use of extracorporeal shock-wave therapy (ESWT) in the treatment of non-unions. A review of the literature. Arch Or- thop Trauma Surg. 2002;122(6):324-330; doi: 10.1007/ s00402-001-0365-4.

6. Huisstede BMA, Gebremariam L, van der Sande R, Hay EM, Koes BW. Evidence for effectiveness of Extracorporal Shock-Wave Therapy (ESWT) to treat calcific and non-calcific rotator cuff tendinosis - a systematic review. Man Ther. 2011;16(5):419-433; doi: 10.1016/j. math.2011.02.005.

7. Tornese D, Mattei E, Lucchesi G, Bandi M, Ricci G, Melegati G. Comparison of two extracorporeal shock wave therapy techniques for the treatment of painful subcalcaneal spur. A randomized controlled study. Clin Rehabil. 2008;22(9):780-787; doi:10.1177/0269215508092819.

8. Böddeker IR, Schäfer H, Haake M. Extracorporeal shockwave therapy (ESWT) in the treatment of plantar fasciitis: a biometrical review. Clin Rheumatol. 2001;20(5):324330; doi: 10.1007/pl00011207.

9. Furia JP, Rompe JD. Extracorporeal shock wave therapy in the treatment of chronic plantar fasciitis and Achilles tendinopathy. Curr Opin Orthop. 2007;18(2):102111; doi: 10.1097/BCO.0b013e328013e594.

10. Menon J, Dorfman HD, Renbaum J, Friedler S. Tarsal tunnel syndrome secondary to neurilemoma of the medial plantar nerve. J Bone Joint Surg Am. 1980;62(2): 301-303.

11. Thomson CE, Crawford F, Murray GD. The effectiveness of extra corporeal shock wave therapy for plantar heel pain: a systematic review and meta-analysis. BMC Musculoskelet Disord. 2005;6:19; doi: 10.1186/14712474-6-19.

12. Hodes R, Larrabee MG, German W. The human electromyogram in response to nerve stimulation and the conduction velocity of motor axons; studies on normal and on injured peripheral nerves. Arch Neurol Psychiatry. 1948;60(4):340-365; doi: 10.1001/archneurpsyc.1948. 02310040011002.

13. Bracilovic A, Nihal A, Houston VL, Beattie AC, Rosenberg ZS, Trepman E. Effect of foot and ankle position on tarsal tunnel compartment volume. Foot Ankle Int. 2006;27(6):431-437;doi:10.1177/107110070602700608.

14. Kaplan PE, Kernahan WT Jr. Tarsal tunnel syndrome: an electrodiagnostic and surgical correlation. J Bone Joint Surg Am. 1981;63(1):96-99.

15. Verstraelen FU, In den Kleef NJ, Jansen L, Morrenhof JW. High-energy versus low-energy extracorporeal shock wave therapy for calcifying tendinitis of the shoulder: which is superior? A meta-analysis. Clin Orthop Relat Res. 2014;472(9):2816-2825; doi: 10.1007/s11999-0143680-0.

16. Butterworth PA, Walsh TP, Pennisi YD, Chesne AD, Schmitz C, Nancarrow SA. The effectiveness of extracorporeal shock wave therapy for the treatment of lower limb ulceration: a systematic review. J Foot Ankle Res. 2015;8:3; doi: 10.1186/s13047-014-0059-0.

17. Wilner JM, Strash WW. Extracorporeal shockwave therapy for plantar fasciitis and other musculoskeletal conditions utilizing the Ossatron - an update. Clin Podiatr Med Surg. 2004;21(3):441-447; doi: 10.1016/j.cpm.2004. 03.002 .

18. Wolff KS, Wibmer A, Pusch M, Prusa AM, Pretterklieber M, Teufelsbauer H, Schaden W. The influence of comorbidities and etiologies on the success of extracorporeal shock wave therapy for chronic soft tissue wounds: midterm results. Ultrasound Med Biol. 2011;37(7):11111119; doi: 10.1016/j.ultrasmedbio.2011.04.007. 
19. Zelle BA, Gollwitzer HF, Zlowodzki MS, Bühren V. Extracorporeal shock wave therapy: current evidence. J Orthop Trauma. 2010;24(Suppl. 1):S66-S70; doi: 10.1097 /BOT.0b013e3181cad510.

20. Wang CJ, Wang FS, Yang KD, Weng LH, Ko JY. Longterm results of extracorporeal shockwave treatment for plantar fasciitis. Am J Sports Med. 2006;34(4):592-596; doi: 10.1177/0363546505281811.

21. Yin MC, Ye J, Yao M, Cui XJ, Xia Y, Shen QX, Tong ZY, Wu XQ, Ma JM, Mo W. Is extracorporeal shock wave therapy clinical efficacy for relief of chronic, recalcitrant plantar fasciitis? A systematic review and meta-analysis of randomized placebo or active-treatment controlled trials. Arch Phys Med Rehabil. 2014;95(8):1585-1593; doi: 10.1016/j.apmr.2014.01.033.

22. Dizon JN, Gonzalez-Suarez C, Zamora MT, Gambito ED. Effectiveness of extracorporeal shock wave therapy in chronic plantar fasciitis: a meta-analysis. Am J Phys Med Rehabil. 2013;92(7):606-620; doi: 10.1097/PHM.0b01 $3 e 31828 c d 42 b$.

23. Wilson M, Stacy J. Shock wave therapy for Achilles tendinopathy. Curr Rev Musculoskelet Med. 2011;4(1):6-10; doi: 10.1007/s12178-010-9067-2.

24. Pipkin FB. Medical statistics made easy. London: Churchill Livingstone; 1984.

25. Wang CJ. Extracorporeal shockwave therapy in musculoskeletal disorders. J Orthop Surg Res. 2012;7:7-11; doi: 10.1186/1749-799X-7-11.

26. Romeo P, d'Agostino MC, Lazzerini A, Sansone VC. Extracorporeal shock wave therapy in pillar pain after carpal tunnel release: a preliminary study. Ultrasound Med Biol. 2011;37(10):1603-1608; doi: 10.1016/j.ultrasmedbio.2011.07.002.

27. Gündüz R, Malas FÜ, Borman P, Kocaoğlu S, Özçakar L. Physical therapy, corticosteroid injection, and extracorporeal shock wave treatment in lateral epicondylitis. Clinical and ultrasonographical comparison. Clin Rheumatol. 2012;31(5):807-812; doi: 10.1007/s10067-012-1939-y.

28. Bolt DM, Burba DJ, Hubert JD, Strain GM, Hosgood GL, Henk WG, Cho DY. Determination of functional and morphologic changes in palmar digital nerves after nonfocused extracorporeal shock wave treatment in horses. Am J Vet Res. 2004;65(12):1714-1718; doi: 10.2460/ ajvr.2004.65.1714.

29. Sems A, Dimeff R, lannotti JP. Extracorporeal shockwave therapy in the treatment of chronic tendinopathy. J Am Acad Orthop Surg. 2006;14(4):195-204; doi: 10.5435/00124635-200604000-00001.

30. Mariotto S, Cavalieri E, Amelio E, Ciampa AR, de Prati AC, Marlinghaus E, Russo S, Suzuki H. Extracorporeal shock waves: from lithotripsy to anti-inflammatory action by NO production. Nitric Oxide. 2005;12(2):89-96; doi: 10.1016/ j.niox.2004.12.005.

31. Hancock CM, Riegger-Krugh C. Modulation of pain in osteoarthritis: the role of nitric oxide. Clin J Pain. 2008; 24(4):353-365; doi: 10.1097/AJP.0b013e31815e5418.

32. Ferreira SH, Duarte ID, Lorenzetti BB. The molecular mechanism of action of peripheral morphine analgesia: stimulation of the cGMP system via nitric oxide release. Eur J Pharmacol. 1991;201(1):121-122; doi: 10.1016/ 0014-2999(91)90333-L.

33. Kosterlitz HW, Wallis DI. The action of morphine-like drugs on impulse transmission in mammalian nerve fibres. Br J Pharmacol Chemother. 1964;22:499-510; doi: 10.1111/j.1476-5381.1964.tb01704.x.
34. Hausner T, Nógrádi A. The use of shock waves in peripheral nerve regeneration: new perspectives? Int Rev Neurobiol. 2013;109:85-98; doi: 10.1016/B978-0-12420045-6.00003-1.

35. Kim JC, Jung SH, Lee SU, Lee SY. Effect of extracorporeal shockwave therapy on carpal tunnel syndrome: a systematic review and meta-analysis of randomized controlled trials. Medicine. 2019;98(33):e16870; doi: 10.1097/MD.0000000000016870.

36. Mahran HG, Mohammed AH, Aboelazm SN. Extracorporeal shockwave therapy for post burn carpal tunnel syndrome. Int J Physiother Res. 2015;3(2):938-946; doi: 10.16965/ijpr.2015.111.

37. Murata R, Ohtori S, Ochiai N, Takahashi N, Saisu T, Moriya H, Takahashi K, Wada Y. Extracorporeal shockwaves induce the expression of ATF3 and GAP-43 in rat dorsal root ganglion neurons. Auton Neurosci. 2006;128(1-2): 96-100; doi: 10.1016/j.autneu.2006.04.003.

38. Wu YH, Liang HW, Chen WS, Lai JS, Luh JJ, Chong FC. Electrophysiological and functional effects of shock waves on the sciatic nerve of rats. Ultrasound Med Biol. 2008;34(10):1688-1696; doi: 10.1016/j.ultrasmedbio. 2008.03.005.

39. Hausner T, Pajer K, Halat G, Hopf R, Schmidhammer R, Redl H, Nógrádi A. Improved rate of peripheral nerve regeneration induced by extracorporeal shock wave treatment in the rat. Exp Neurol. 2012;236(2):363-370; doi: 10.1016/j.expneurol.2012.04.019.

40. Vahdatpour B, Kiyani A, Dehghan F. Effect of extracorporeal shock wave therapy on the treatment of patients with carpal tunnel syndrome. Adv Biomed Res. 2016; 5:120; doi: 10.4103/2277-9175.186983. 